\title{
Type II Collagen N-Telopeptide Measurement
}

National Cancer Institute

\section{Source}

National Cancer Institute. Type II Collagen N-Telopeptide Measurement. NCI Thesaurus.

Code C82041.

The determination of the amount of the type II collagen $\mathrm{N}$-telopeptide present in a sample. 